\title{
Taxonomy of the extra-solar planet
}

\author{
Eva Plávalová \\ Dpt. of astronomy, Earth‘s physics, and meteorology, Comenius University, Bratislava, Slovakia \\ e-mail: plavala@slovanet.sk
}

Received 7 July, 2011 / Accepted 20 February 2012

\begin{abstract}
When a star is described as a spectral class G2V, we know that the star is similar to our Sun. We know its approximate mass, temperature, age, and size. When working with an extra-solar planet database, it is very useful to have a taxonomy scale (classification) such as, for example, the Harvard classification for stars. The taxonomy has to be easily interpreted and present the most relevant information about extra-solar planets. I propose the following the extra-solar planet taxonomy scale with four parameters. The first parameter concerns the mass of an extra-solar planet in the form of the units of the mass of other known planets, where $\mathrm{M}$ represents the mass of Mercury, E that of Earth, $\mathrm{N}$ Neptune, and J Jupiter. The second parameter is the planet's distance from its parent star (semi-major axis) described in logarithm with base 10. The third parameter is the mean Dyson temperature of the extra-solar planet, for which I established four main temperature classes; F represents the Freezing class, W the Water Class, G the Gaseous Class, and R the Roasters Class. I devised one additional class, however: P, the Pulsar Class, which concerns extra-solar planets orbiting pulsar stars. The fourth parameter is eccentricity. If the attributes of the surface of the extrasolar planet are known, we are able to establish this additional parameter where t represents a terrestrial planet, $\mathrm{g}$ a gaseous planet, and $\mathrm{i}$ an ice planet. According to this taxonomy scale, for example, Earth is 1E0W0t, Neptune is 1N1.5F0i, and extra-solar planet 55 Cnc e is 9E-1.8R1. Key words: Catalogues - Extrasolar planet - Habitable zone - Planets
\end{abstract}

\section{Introduction}

Astronomical papers, for the most part, specify the spectral type of stars in the first reference according to the Harvard spectral classification. When this information is known, the effective temperature of the star, its color, mass, and radius can be roughly estimated. Unfortunately, a taxonomy scale for extrasolar planets (EPs) similar to the Harvard classification for stars does not exist. We know of more than 700 EPs (as of December 2011). Moreover, Borucki et al. (2011) nominated more than 1,200 candidates for EPs from analysis of only the first four month's data. It would be helpful to investigators if a simple and comprehensive taxonomy were available when working with a large number of EPs. Some labeling for Eps has been implemented; close-in planets, for example, have been identified and so labeled, as have giant planets, Jovian planets, hot-Jupiters, hot planets, "Neptune-mass planets, Saturn-mass planets, rocky planets, and superEarths. This labeling has contributed to the development of our knowledge of EPs and enabled investigators to identify different types of EPs simultaneously. However, a label such as "Neptune-mass planet," could refer to a close-in planet or to an ice planet as well. Other, more precise identification labels have entered into the lexicon, such as a close-in terrestrial planet (Haghighipour and Rastegar 2011), but by and large, a general taxonomy for EPs is yet to be established.

There are three different taxonomies in astronomy. The first was proposed by Sudarsky, Burrows, and Hubeny (2003), the second was created by Marchi (2007), and a third taxonomy was projected by Lundock et al. (2009). All these taxonomies have a benchmark in the spectrum of EPs. These are very precise taxonomies, but the initial quick data about an EP is very complicated and does not indicate the main features of EPs. Our proposal is that taxonomy data of a particular EP should be easily comparable to that of others.

\section{Taxonomy}

To establish the general features of the EP, it is requisite that, at the very least, the planet's mass and semi-major axis is known. It is helpful if the eccentricity, temperature characteristics, period, radius, and density 
are known as well. The seven parameters mentioned here, however, are too numerous and involved to be included in a comprehensible and comparable taxonomy. Temperature is the only parameter used in the Harvard classification. A star's mass, however, which is closely related to its temperature, is the most important condition for its evolution. For this reason only one parameter in a star's classification is necessary. Today's research indicates that, for Eps, more than one parameter for their evolution is needed.

I endeavored to choose the most important features of EPs as parameters for the proposed taxonomy. I selected the following five parameters: mass, semi-major axis, mean Dyson temperature, eccentricity, and surface attributes.

\subsection{Mass of the extra-solar planet}

It is thought that the most important parameter of an EP is its mass. The first parameter of taxonomy is information that concerns the mass of an EP. The mass of Jupiter is currently used as a benchmark mass unit for EPs. It is assumed that many more EPs will be discovered with masses less than that of Earth and possibly less than that of Mercury. I have established the units of the mass of some known planets in the Solar system. For EPs with a mass less than $0.003 \mathrm{M}_{\text {Jup }}$, we established the mass unit of Mercury $\left(3.302 \times 10^{23} \mathrm{~kg}\right)$. We are aware of EPs with a mass in this category. For EPs with a mass between $0.003 \mathrm{M}_{\text {Jup }}$ and $0.05 \mathrm{M}_{\text {Jup }}$, we established a mass unit scale of the Earth $\left(5.9736 \times 10^{24}\right.$ $\mathrm{kg}$ ). There are at least ten known EPs with a mass in this category. The group of EPs known as super-Earths is members of this mass unit. For EPs with a mass between $0.05 \mathrm{M}_{\text {Jup }}$ and $0.99 \mathrm{M}_{\text {Jup }}$, we established a mass unit scale of Neptune $\left(1.0243 \times 10^{26} \mathrm{~kg}\right)$. Of these EPs, there are quite a large number; more than a hundred. For the EPs with a mass more than $1 \mathrm{M}_{\text {Jup }}$ we used the mass unit scale of Jupiter $\left(1.8986 \times 10^{27} \mathrm{~kg}\right)$. In this category, there are currently the largest numbers of EPs.

The form of this parameter in taxonomy is the integer number of the mass unit and the first letter of the planet it corresponds to, where M represents Mercury, E Earth, $\mathrm{N}$ Neptune, and J Jupiter. For example, Earth is 1E, Neptune is $1 \mathrm{~N}$, Uranus 15E, and $55 \mathrm{Cnc}$ e $9 \mathrm{E}$.

\subsection{Semimajor axis}

The position of an EP in its stellar system is the next very important parameter that influences many other features of this celestial body. For this reason, the second parameter of taxonomy is the distance between the EP and its parent star in astronomical units (AU). Initially, I had hoped to define this parameter in two different ways: one for a semi-major axis less than $1 \mathrm{AU}$ different and another for a semi-major axis greater than
1 AU. For a semi-major axis less than 1 AU, I wanted to use a decimal number with one decimal position, and for a semi-major axis less than $0.1 \mathrm{AU}$, I wanted to use a decimal number with two decimal positions. For a semimajor axis greater than $1 \mathrm{AU}$, I wanted to use an integer number. However, it became clear that this method would result in a complicated and unclear outcome.

In the end, I chose to define the second parameter in logarithm form ${ }^{1}$.I used a logarithm with base 10 from a semi-major axis and rounded the calculated value to the nearest decimal point. For EPs with a semi-major axis smaller than $1 \mathrm{AU}$, this parameter is negative, and with the decreasing value of a semi-major axis, the value of this parameter rapidly decreases to -2 . Smaller values than -2 (semi-major axis is 0.01), at present, are unexpected. For the value of a semi-major axis equal to $1 \mathrm{AU}$, the value of this parameter is 0 . For a semi-major axis with a value greater than 1, the value of this parameter is positive. For example, the value of a semimajor axis equal to $10 \mathrm{AU}$ has a parameter value of 1 , and for a semi-major axis with a value of $100 \mathrm{AU}$, this parameter is 2 .

For example, for Earth this parameter has the form of 0 , for Neptune the form is 1.5 , Uranus $1.3,55 \mathrm{Cnc}$ c -0.6 (the semi-major axis is $0.2403 \mathrm{AU}$ ), and $55 \mathrm{Cnc}$ e is -1.8 (the semi-major axis is $0.0156 \mathrm{AU}$ ).

\subsection{Mean Dyson temperature}

The value of the surface temperature of an EP depends on many parameters, for example, albedo, speed of the rotation of the EP, or the structure of its atmosphere. A precise temperature value of an EP cannot be determined from observable data. It was necessary to establish a new universal parameter for the temperature in taxonomy, which could be determined for most known EPs.

By using the Stefan-Boltzmann law, the flux on the surface of a parent star can be expressed as

$$
L=4 \pi R_{*}^{2} T_{*}^{4} \zeta
$$

where $R_{*}$ is the radius of the star, $T_{*}$ the effective temperature of the star, and $\zeta$ the Stefan-Boltzmann constant. An effective radiating temperature for a planet, which is rotating slowly, can be calculated by the following equation (e.g., Karttunen et al. 2003):

$$
T=T_{*}\left(\frac{1-A}{2}\right)^{1 / 4}\left(\frac{R_{*}}{R_{E P}}\right)^{1 / 2} .
$$

\footnotetext{
${ }^{1}$ Y. Dutil (Chaire de recherche industrielle en technologies de l'énergie et en e_cacité énergétique (T3E) École de Technologie Supérieure) private communication
} 
Here, $R_{E P}$ is the distance from the parent star to the EP, and $A$ is Bond albedo of the planet. An effective radiating temperature for a planet that is rotating quickly is

$$
T=T_{*}\left(\frac{1-A}{4}\right)^{1 / 4}\left(\frac{R_{*}}{R_{E P}}\right)^{1 / 2}
$$

For the EP, it can generally be said that the planet orbits quickly, and the temperature can be calculated by equation (3). Even so, it is possible that close-in planets with a very short period have a synchronous rotation, and equation (2) must be used as opposed to equation (3). This ambiguous fact leads to the establishment of a new parameter: the Dyson temperature. It is a temperature that has an artificial sphere the size of a planetary orbit (Dyson sphere) (Dyson 1960), which can be defined according to the following equation.

$$
T_{E P}^{4}=\frac{T_{*}^{4} R_{*}^{2}}{R_{E P}^{2}}
$$

For an EP with a small value of eccentricity, equation (4) can be used directly. However, in the case when an EP has a large value of eccentricity, the distance from the parent star changes, according to the Second Keplerian law, without homogeneity and in many cases rapidly. In some cases, the Dyson temperature changes very rapidly, too. For better precision of the calculation of the Dyson temperature, I divided the EP's orbit into ten equal segments, according to the time needed for a complete rotation. For this calculation, I used the Kepler equation. For the calculation of the eccentric anomaly, I used an iteration method with three steps (see e.g. Andrle, 1971) and calculated the value of the momentary distance of an EP from its parent star, using the following equation (see e.g. Karttunen et al. 2003):

$$
R_{E P}=a(1-e \cos E)
$$

Here, $a$ is the semi-major axis, $e$ the eccentricity, and $E$ the eccentric anomaly of an EP. I used this value of distance in equation (4) and calculated the momentary Dyson temperature. I calculated the Dyson temperature for ten equal segments, according to the second Keplerian law, and from these ten values, I calculated the arithmetical mean, which I defined as the mean Dyson temperature $\left(t_{E P}\right)$ for the EP.

For EPs for which the value of their albedo and speed of rotation are known, their effective radiating temperature can be calculated by

$$
T=\left(\frac{1-A}{2}\right)^{1 / 4} t_{E P},
$$

\section{for planets with a slow rotation, and by}

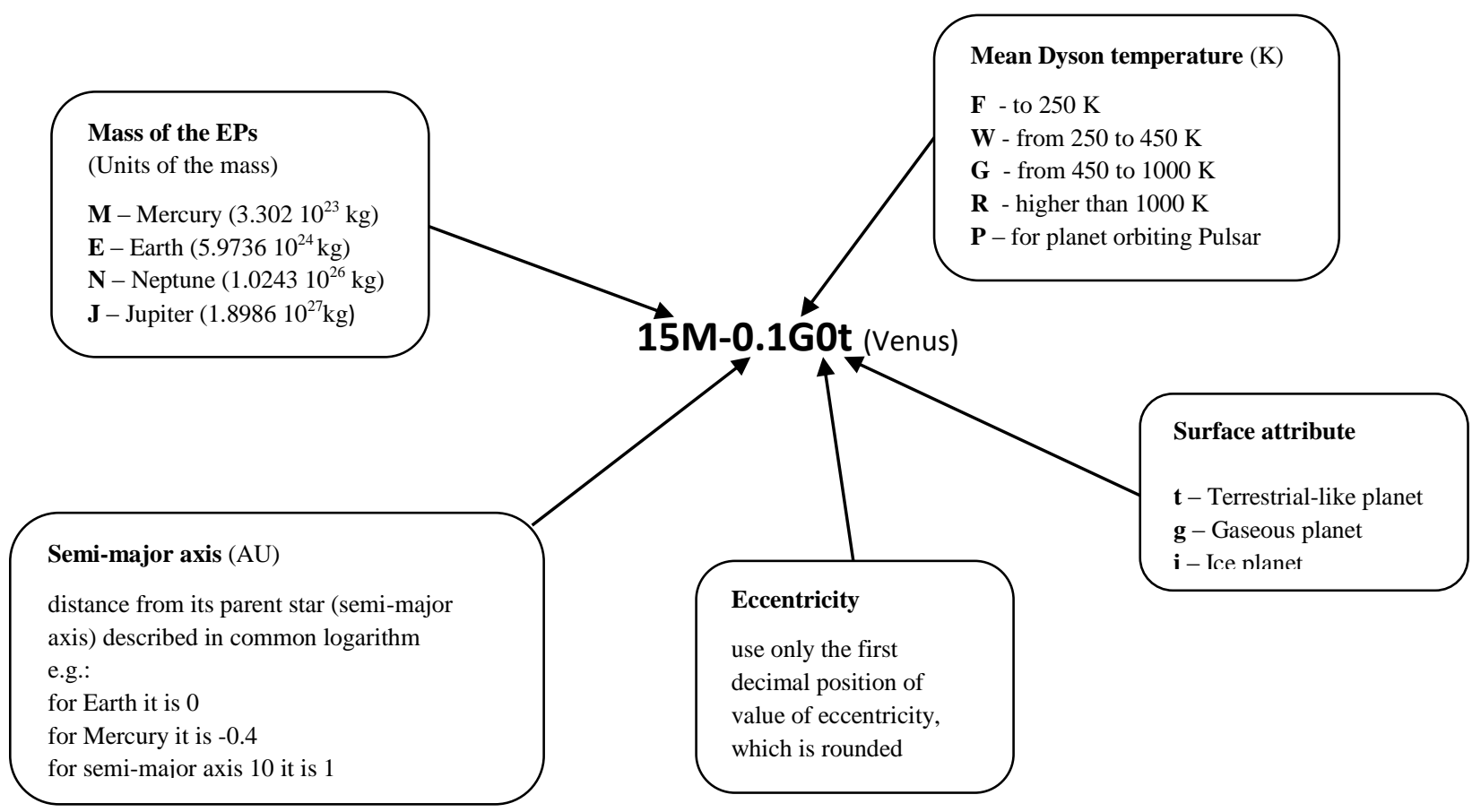

Figure 1: Schematic explanation - a definition of the taxonomy of the EPs for which we are able to determine the taxonomy scale. 
Table 1: Five EPs in system 55 Cnc (HD75732).

\begin{tabular}{llllll}
\hline Name & $55 \mathrm{Cnc} \mathrm{b}$ & $55 \mathrm{Cnc} c$ & $55 \mathrm{Cnc} d$ & 55 Cnc e & 55 Cnc f \\
\hline \hline Taxonomy & $15 \mathrm{~N}-0.9 \mathrm{R} 0$ & $3 \mathrm{~N}-0.6 \mathrm{G} 1$ & $4 \mathrm{~J} 0.8 \mathrm{~F} 0$ & 9E-1.8R1 & 3N-0.1W0 \\
Mass [M $_{J u p}$ ] & 0.824 & 0.169 & 3.835 & 0.027 & 0.144 \\
Semi-major axis [AU] & 0.1148 & 0.2403 & 5.76 & 0.0156 & 0.781 \\
Logarithm from Semi-major axis & -0.94 & -0.62 & 0.76 & -1.81 & -0.11 \\
Mean Dyson temperature [K] & 1010.0 & 698.0 & 142.6 & 2739.4 & 387.2 \\
Eccentricity & 0.0159 & 0.053 & 0.025 & 0.057 & 0.0002 \\
Period [days] & 14.651262 & 44.3446 & 5218 & 0.73654 & 260.7 \\
\hline
\end{tabular}

$$
T=\left(\frac{1-A}{4}\right)^{1 / 4} t_{E P}
$$

for planets with a quick rotation.

For example, the mean Dyson temperature of Earth is $392 \mathrm{~K}$ and the albedo is 0.3. With equation (7), the effective radiating temperature is $254 \mathrm{~K}$.

For a clearer differentiation, I established four main temperature classes. The coldest class is the Freezing class, which is indicated as $\mathbf{F}$. The members of this class have a mean Dyson temperature less than $250 \mathrm{~K}$. Jupiter, Saturn, Neptune, and Uranus are members of this class. The second class is the Water class, and it is indicated as W. Members of this class have a mean Dyson temperature that ranges from 250 to $450 \mathrm{~K}$. An EP from this class could have liquid water at its surface. Earth and Mars are members of this class. For the third class, the mean Dyson temperature ranges from 450 to $1000 \mathrm{~K}$. This is termed the Gaseous Class and is indicated as G. Mercury and Venus are members of this class. And finally, the fourth class is the hottest class and comprised of planets with a mean Dyson temperature higher than $1000 \mathrm{~K}$. This class was aptly named the Roasters Class and it is indicated as R. Many the members of this class are called close-in planets.

I defined the Water class as planets that reside in the Habitable zone (HZ), as defined by Kasting, Whitmire, and Reynolds (1993). These authors purported conservative estimates of $\mathrm{HZ}$ boundaries to be $0.95 \mathrm{AU}$ for the inner edge closest to the sun and 1.37 AU for the outer edge. It should be noted that Michna et al. (2000) calculated that the outer boundary could be at distances as great as $2.4 \mathrm{AU}$, and Dole (1970) marked the inner boundaries as 0.725 AU. I used the "optimistic" boundaries 0.725 and 2.4 AU for the definition of the Water class. The value of the mean Dyson temperature for a hypothetical planet with the same parameter as Earth and orbits with a semi-major axis of $0.725 \mathrm{AU}$ is $460 \mathrm{~K}$. This value for a hypothetical planet with the same parameter as Earth, but with a=2.4 AU, is 253 $\mathrm{K}$. Considering the fact that the boundaries of the $\mathrm{HZ}$ are not expressly defined, I established the range of the mean Dyson temperature for the Water class to be $250 \mathrm{~K}$ to $450 \mathrm{~K}$.

It is known that some EPs orbit pulsar stars. For such these EPs, I predicted that their behavior would be totally different than that of EPs that orbit stars in the main sequence. I could not calculate the mean Dyson temperature of these EPs and so created an additional class, named the Pulsar class, which is indicated as $\mathbf{P}$.

\subsection{Eccentricity}

As shown in the previous paragraph, the eccentricity of an EP is the next very important behavioral characteristic I included in the taxonomy as the fourth parameter. For easier reference, I used only the first decimal position for the value of eccentricity, which is rounded. 


\subsection{Surface attribute}

Generally speaking, an EP's surface characteristics can not be defined; however, an improvement of observation equipment wouldallow for better and more precise data and specification of surface characteristics for many EPs in the future. For this reason, I considered a fifth additional parameter in taxonomy: the surface attribute.

I considered three different surface attributes, according to the type of surfaces that have been observed in the Solar system. The first surface attribute is a terrestrial-like planet surface. Mercury, Venus, Mars, and of course Earth have terrestrial-like planet surfaces, and this attribute is indicated as a lower case $\mathbf{t}$. The second surface attribute is a gaseous planet surface, such as that of Jupiter and Saturn. I indicated this attribute with a lower case g. The third surface attribute is an ice planet surface similar to that of Uranus and Neptune. This attribute is indicated as a lower case $\mathbf{i}$.

It is assumed that, as we begin to detect EPs with a mean Dyson temperature above or below that found in the Solar system, more and more EPs will emerge with different surface attributes, which will have to be defined. The possibilities are endless and may include, for example, surfaces of ocean water surface or magma. This is unheard of for us at our present level of understanding.

\section{Interpretation examples}

With all the necessary parameters defined, I considered a structure for taxonomy. Below, I present my proposed taxonomy with a sample planet from the Solar System, Venus.

The taxonomy class for Venus is 15M-0.1G0t. That is,

$15 \mathbf{M}$ - The mass of Venus is fifteen times greater than Mercury's mass. Precisely put, the mass

of Venus is $4.8685 \times 10^{24} \mathrm{~kg}$, roughly 15 times more than the mass of Mercury.

$\mathbf{- 0 . 1}$ - Venus's semi-major axis is 0.723 AU. Logarithm with base 10 from this value is 0.1 .

G - The mean Dyson temperature is between $450 \mathrm{~K}$ and $1000 \mathrm{~K}$. The exact Dyson orbit temperature is $461 \mathrm{~K}$.

$\mathbf{0}$ - Venus is orbiting on a near-circle orbit with an eccentricity value of 0.0068 .

$\mathbf{t}$ - Venus has a solid surface, which we can say is a terrestrial planet surface.

The taxonomy class for the first discovered extra-solar planet orbiting a main sequence star $51 \mathrm{Peg} b$ is $\mathbf{9 N - 1 . 3 R 0 . ~ T h a t ~ i s , ~}$

9N - The mass of 51Peg b is $0.468 \mathrm{M}_{\text {Jup }}$, which is $8.67 \mathrm{M}_{\text {Nep }}$ (mass of Neptune).

-1.3 - The b semi-major axis of $51 \mathrm{Peg} b$ is 0.052 AU. Logarithm with base 10 from this value is -1.3 .

Table 2: Register for EPs orbiting one of the stars in these binary stellar systems.

\begin{tabular}{|c|c|c|c|c|c|c|}
\hline Name & 70 Vir b & eps Eridani Ab & $\begin{array}{l}\text { eps Eridani Ac } \\
\text { (unconfirmed) }\end{array}$ & $\begin{array}{l}\text { gama Cephei b } \\
\text { (HD 222404) }\end{array}$ & $\mathrm{HD} 142 \mathrm{Ab}$ & $\begin{array}{l}\text { tau Boo b } \\
\text { (HD 120136 b) }\end{array}$ \\
\hline Taxonomy & $7 \mathrm{~J}-0.3 \mathrm{G} 4$ & $2 \mathrm{~J} 0.5 \mathrm{~F} 7$ & 2N1.6F3 & 2J0.3G0 & $1 \mathrm{~J} 0 \mathrm{~W} 4$ & 4J-1.3R0 \\
\hline Planet mass $\left[\mathrm{M}_{J u p}\right]$ & 6.6 & 1.55 & 0.1 & 1.85 & 1.03 & 3.9 \\
\hline Semi-major axis [AU] & 0.48 & 3.39 & 40 & 2.05 & 1 & 0.046 \\
\hline Logarithm from Semi-major axis & -0.32 & 0.53 & 1.60 & 0.31 & 0.0 & -1.34 \\
\hline Mean Dyson temperature [K] & 737.1 & 51.6 & 174.8 & 503.2 & 385.3 & 2301.7 \\
\hline Eccentricity & 0.43 & 0.702 & 0.3 & 0.040 & 0.37 & 0.018 \\
\hline Period [days] & 116.67 & 2502 & 102270 & 903.3 & 339 & 3.3135 \\
\hline Spectral class parent star & G4V & $\mathrm{K} 2 \mathrm{~V}$ & $\mathrm{~K} 2 \mathrm{~V}$ & $\mathrm{~K} 2 \mathrm{~V}$ & G1 IV & F7V \\
\hline Mother star mass $\left[\mathrm{M}_{\text {Sun }}\right]$ & 0.92 & 0.83 & 0.83 & 1.4 & 1.1 & 1.3 \\
\hline $\mathrm{T}_{E f f}$ parent star $[\mathrm{K}]$ & 5432 & 5116 & 5116 & 4800 & 6180 & 6309 \\
\hline Radius parent star $\left[\mathrm{R}_{S u n}\right]$ & 1.968 & 0.895 & 0.895 & 4.9 & 0.86 & 1.331 \\
\hline
\end{tabular}


$\mathbf{R}$ - The mean Dyson temperature is higher than $1000 \mathrm{~K}$; more precisely, it is $1938.6 \mathrm{~K}$.

0 - The EP 51 Peg b is orbiting on a circle or near circle orbit. The value is precisely 0 .

The surface attribute parameter is mentioned only in the case when we can specify it.

The method of taxonomy as schematically explained is in Figure 1.

\section{Practical examples}

When working with large groups of EPs, it is practically impossible to compare them by using an easy and quick mechanism. For example, there are five EPs in the planetary system $55 \mathrm{Cnc}$. Without quite a wide table, it is impossible to say which EP is the smallest, which has the farthest or the closest orbit, or which planet has the most eccentric orbit, etc. Using our taxonomy, one can answer these questions practically immediately. For example, the closest planet is $55 \mathrm{Cnc}$ e with a semi-major axis of about $0.02 \mathrm{AU}$ (exactly written $0.0156 \mathrm{AU}$ ). We can immediately say that the value of the eccentricity for $55 \mathrm{Cnc} \mathrm{c}$ and $55 \mathrm{Cnc}$ e is nearly the same (the exact eccentricity for $55 \mathrm{Cnc} \mathrm{c}$ is 0.053 and the eccentricity for $55 \mathrm{Cnc} \mathrm{e}$ is 0.057 ). The data and taxonomy identification regarding EP members of the system $55 \mathrm{Cnc}$ are in Table 1.

The application of this taxonomy for EPs with a different parent star is quite significant. For example, we can compare EPs that host one of the members of the binary stellar systems. We know more than sixty systems with such a condition. The data for several EPs orbiting one of the stars in a binary stellar system are in Table 2 . We only need the first line of the table to say which EP from this group is the heaviest (70 Vir b), which one is the hottest (tau Boo b), or which has the most distant orbit (eps Eridani Ac), along with many other features.

The data and taxonomy identification for a few example EPs are shown in Table 3, and the taxonomy identification for other known EPs that we can classified are in Table 4.

\section{Conclusion}

I have endeavored to build a taxonomy scale for EPs that, first, could be used as a quick and easy mechanism to determinate the main attributes for an EP and, second, allow for a quick and clear comparison of large numbers of EPs. The taxonomy scale of EPs for which we know the values for mass, semi-major axis, and eccentricity can be determined along with the values for the radius and effective temperature of their parent stars. Almost 500 known EPs have been found with this condition. For rapid determination and understanding of the taxonomy of an EP, a graphic guide is shown in Figure 1 in which the method purported here for defining the taxonomy identification of an EP is schematically interpreted

\section{Acknowledgments}

I am grateful to Y. Dutil and anonymous referees for their informative comments and suggestions that helped to improve the content.

\section{References}

Andrle, P. (1971) Základy nebeské mechaniky. Academia Praha.

Borucki, W.J., Koch, D.G., Basri, G., Batalha, N., Brown, T.M., Bryson, S.T., Caldwell, D., Christensen-Dalsgaard, J., Cochran, W.D., DeVore, E., Dunham, E.W., Gautier, T.N., Geary, J.C., Gilliland, R., Gould, A., Howell, S.B., Jenkins, J.M., Latham, D.W, Lissauer, J.J., Marcy, G.W., Rowe, J., Sasselov, D., Boss, A., Charbonneau, D., Ciardi, D., Doyle, L., Dupree, A.K., Ford, E.B., Fortney, J., Holman, M.J., Seager, S., Steffen, J.H., Tarter, J., Welsh, W.F., Allen, Ch., Buchhave, L.A., Christiansen, J.L., Clarke, B.D., Das, S., Désert, J-M., Endl, M., Fabrycky, D., Fressin, F., Haas, M., Horch, E., Howard, A., Isaacson, H., Kjeldsen, H., Kolodziejczak, J., Kulesa, C., Li, J., Lucas, P.W., Machalek, P., McCarthy, D., MacQueen, P., 
Meibom, S., Miquel, T., Prsa, A., Quinn, S.N., Quintana, E.V., Ragozzine, D., Sherry, W., Shporer, A., Tenenbaum, P., Torres, G., Twicken, J.D., Van Cleve, J., Walkowicz, L., Witteborn, F.C., and Still, M. (2011) Characteristics of planetary candidates observed by Kepler, II: Analysis of the first four months of data. Available online at http://arxiv.org/abs/arxiv:1102.0541v2.

Bouchy, F., Mayor, M., Lovis, C., Udry, S., Benz, W., Bertaux, J.L., Delfosse, X., Mordasini, C., Pepe, C., Queloz, D., and Segransan, D. (2009) The HARPS search for southern extra-solar planets: XVII. Super-Earth and Neptune-mass planets in multiple planet systems HD 47186 and HD 181433. Astronomy \& Astrophysics 496.2:527-531.

Correia, A.C.M., Udry, S., Mayor, M., Benz, W., Bertaux, J.-L., Bouchy, F., Laskar, J., Lovis, C., Mordasini, C., Pepe, F., and Queloz, D. (2009) The HARPS search for southern extra-solar planets: XVI. HD45364, a pair of planets in a 3:2 mean motion resonance. Astronomy \& Astrophysics 496.2:521-526.

Dole, S.H. (1970) Habitable Planets for Man. 1st ed. New York: Elesvier.

Dyson, F.J. (1960) Search for Artificial Stellar Source of Infra-Red Radiation. Science 131 (3414): 1667-1668.

Forveille, T., Bonfils, X., Delfosse, X., Gillon, M., Udry, S., Bouchy, F., Lovis, C., Mayor, M., Pepe, F., Perrier, C., Queloz, D., Santos, N., and Bertaux, J.-L. (2009) The HARPS search for southern extra-solar planets: XIV. Gl 176b, a super-Earth rather than a Neptune, and at a different period. Astronomy \& Astrophysics 493.2:645-650.

Haghighipour, N. and Rastegar, R. (2011) Implications of the TTV-detection of close-in terrestrial planets around $\mathrm{M}$ stars for their origin and dynamical evolution. Proceedings of Haute Provence Observatory Colloquium (23-27 August 2010). Available online at http://arxiv.org/abs/1012.2183.

Karttunen, H., Kröger, P., Oja, H., and Donner, K.J. (2003) Fundamental astronomy. 4th ed. Springer-Verlag Berlin Heidelberg.

Kasting, J.F., Whitmire D.P., and Reynolds R.T. (1993) Habitable zone around Main Sequence Stars. Icarus 101:108-128.
Lo Curto, G., Mayor, M., Benz, W., Bouchy, F., Lovis, C., Moutou, C., Naef, D., Pepe, F., Queloz, D., Santos, N.C., Segransan, D., and Udry, S. (2010) The HARPS search for southern extrasolar planets: XXII. Multiple planet systems from the HARPS volume limited sample. Astronomy \& Astrophysics 512:A48, doi: 10.1051/00046361/200913523.

Lovis, C., Mayor, M., Bouchy, F., Pepe, F., Queloz, D., Santos, N.C., Udry, S., Benz, W., Bertaux, J.-L., Mordasini, C., and Sivan, J.-P (2005) The HARPS search for southern extrasolar planets: III. Three Saturnmass planets around HD 93083, HD101930 and HD 102117. Astronomy \& Astrophysics 437.3:1121-1126.

Lundock, R., Ichikawa, T., Okita, H., Kurita, K., Kawabata, K.S., Uemura, M., Yamashita, T., Ohsugi, T., Sato, S., and Kino, M. (2009) Tohoku-Hiroshima-Nagoya planetary spectra library: a method for characterizing planets in the visible to near infrared. Astronomy \& Astrophysics 507.3:1649-1658.

Marchi, S. (2007) Extrasolar Planet Taxonomy: A New Statistical Approach. The Astrophysical Journal 666.1:475-485.

Mayor, M., Udry, S., Naef, D., Pepe, F., Queloz, D., Santos, N.C., and Burnet, M. (2004) The CORALIE survey for southern extra-solar planets: XII. Orbital solutions for 16 extra-solar planets discovered with CORALIE. Astronomy \& Astrophysics 415.1:391-402.

Michna, M.A. Kasting, J.F., Pavlov, A.. and Freedman, R. (2000) Influence of Carbon Dioxine Clouds on Early Martina Climate. Icarus 145:546-554.

Moutou, C., Mayor, M., Bouchy, F., Lovis, C., Pepe, F., Queloz, D., Santos, N.C, Udry, S., Benz, W., Lo Curto, G., Naef, D., Ségransan, D., and Sivan, J.-P. (2005) The HARPS search for southern extra-solar planets: IV. Three close-in planets around HD 2638, HD 27894 and HD63454. Astronomy \& Astrophysics 439.1:367373.

Moya, A., Amado, P.J., Barrado, D., García Hernández, A., Aberasturi, M., Montesinos, B., Aceituno, F (2005) Age determination of the HR 8799 planetary system using asteroseis-mology. Available online at 
Naef, D., Mayor, M., Benz, W., Bouchy, F., Lo Curto, G., Lovis, C., Moutou, C., Pepe, F., Queloz, D., Santos, N.C., and Udry, S. (2007) The HARPS search for southern extra-solar planets: IX. Exoplanets orbiting HD 100777 , HD 190647 , and HD221287. Astronomy \& Astrophysics 470.2:721-726.

Niedzielski, A., Konacki, M., Wolszczan, A., Nowak, G., Maciejewski, G., Gelino, C.R., Shao, M., Shetrone, M., and Ramsey L.W. (2007) A Planetary-Mass Companion to the K0 Giant HD 17092. The Astrophysical Journal 669.2:13541358.

Pepe, F., Mayor, M., Queloz, D., Benz, W., Bonfils, X., Bouchy, F., Lo Curto, G., Lovis, C., Mégevand, D., Moutou, C., Naef, D., Rupprecht, G., Santos, N.C., Sivan, J.P., Sosnowska, D., and Udry, S. (2004) The HARPS search for southern extra-solar planets: I. HD 330075 b: A new "hot Jupiter". Astronomy \& Astrophysics 423.1:385-389.

Santos, N. C., Mayor, M., Benz, W., Bouchy, F., Figueira, P., Lo Curto, G., Lovis, C., Melo, C., Moutou, C., Naef, D., Pepe, F., Queloz, D., Sousa, S.G., and Udry. S. (2010) The HARPS search for southern extra-solar planets: XXI. Three new giant planets orbiting the metal-poor stars HD5388, HD 181720, and HD 190984. Astronomy \& Astrophysics 512:A47, doi: 10.1051/0004-6361/200913489.
Sato, B., Fischer, D.A., Ida, S., Harakawa, H., Omiya, M., Johnson, J.A., Marcy, G.W., Toyota, E., Hori, Y., Isaacson, H., Howard, A.W., and Peek, K.M.G (2009). A Substellar Companion in a 1.3 yr Nearly-circular Orbit of HD 16760. Available online http://arxiv.org/abs/0907.5080v1.

Schneider, J., Dedieu, C., Le Sidaner, P., Savalle, R., Zolotukhin, I. (2011) Defining and cataloging exoplanets: The exoplanet.eu database. Astronomy \& Astrophysics 532:A79, doi: 10.1051/0004-6361/201116713.

Sudarsky, D., Burrows, A., and Hubeny, I. (2003) Theoretical Spectra and Atmospheres of Extrasolar Giant Planets. Astronomy \& Astrophysics 588.2:1121, doi 10.1086/374331.

Tamuz, O., Ségransan, D., Udry, S., Mayor, M., Eggenberger, A., Naef, D., Pepe, F., Queloz, D., Santos, N.C., Demory, B.-O., Figuera, P., Marmier, M., and Montagnier, G. (2008) The CORALIE survey for southern extra-solar planets - XV. Discovery of two eccentric planets orbiting HD 4113 and HD 156846. Astronomy \& Astrophysics 480.3:L33-L36.

Zucker, S., Mazeh, T., Santos, N.C., Udry, S., and Mayor, M. (2003) Multi-order TODCOR: Application to observations taken with the CORALIE echelle spectrograph - I. The system HD 41004. Astronomy \& Astrophysics 404.2:775-781. 
Table 3: The data and taxonomy identification for a few example EPs.

\begin{tabular}{|c|c|c|c|c|c|c|c|c|c|c|c|c|c|}
\hline Star & $\begin{array}{l}\text { spect. } \\
\text { class }\end{array}$ & $\begin{array}{l}\mathrm{M}_{*} \\
\left(\mathrm{M}_{\text {Sun }}\right) \\
\end{array}$ & $\begin{array}{l}\mathrm{T} * \\
(\mathrm{~K}) \\
\end{array}$ & $\begin{array}{l}\mathrm{R}_{*} \\
\left(\mathrm{R}_{\text {Sun }}\right) \\
\end{array}$ & Planet & $a_{p l a n}$ & $\log \left(a_{\text {plan }}\right)$ & $\mathrm{e}_{\text {plan }}$ & $\begin{array}{l}\mathrm{M}_{\text {plan }} \\
\left(\mathrm{M}_{\text {Jup }}\right) \\
\end{array}$ & $\begin{array}{l}\text { Period } \\
\text { (day) }\end{array}$ & $\begin{array}{l}\text { Mean Dyson } \\
\text { temp. (K) }\end{array}$ & Taxonomy & Ref. \\
\hline CoRoT-7 & K0V & 0.93 & 5275 & 0.87 & CoRoT-7 d & 0.08 & -1.097 & 0 & 0.052 & 9.021 & 1179.8 & 17E-1.1R0 & \\
\hline eps Eridani A & $\mathrm{K} 2 \mathrm{~V}$ & 0.83 & 5116 & 0.895 & eps Eridani A $c^{u}$ & 40 & 1.602 & 0.3 & 0.1 & 102270 & 51.6 & 2N1.6F3 & \\
\hline HAT-P-13 & G4 & 1.22 & 5638 & 1.56 & HAT-P-13 d ${ }^{\mathrm{u}}$ & 0.056 & -1.252 & 0 & 0.016 & 4.37 & 2018.2 & $5 \mathrm{E}-1.3 \mathrm{R} 0$ & \\
\hline HD 100777 & K0 & 1 & 5582 & $1.0979^{\mathrm{a}}$ & HD 100777 b & 1.03 & 0.013 & 0.36 & 1.16 & 383.7 & 387.6 & 1J0W4 & 1 \\
\hline HD 101930 & K1V & 0.74 & 5079 & $0.9259^{\mathrm{a}}$ & HD $101930 \mathrm{~b}$ & 0.302 & -0.520 & 0.11 & 0.3 & 70.46 & 602.7 & $6 \mathrm{~N}-0.5 \mathrm{G} 1$ & 2 \\
\hline HD 111232 & G8V & 0.78 & 5494 & $0.9187^{\mathrm{a}}$ & HD $111232 b$ & 1.97 & 0.294 & 0.2 & 6.8 & 1143 & 253.8 & 7J0.3W2 & 3 \\
\hline HD 1461 & G0V & 1.08 & 5765 & 1.095 & HD $1461 \mathrm{e}^{\mathrm{u}}$ & 1.165 & 0.066 & 0.74 & 0.072 & 454 & 373.0 & $1 \mathrm{~N} 0.1 \mathrm{~W} 7$ & \\
\hline HD 1461 & G0V & 1.08 & 5765 & 1.095 & HD $1461 \mathrm{~d}^{\mathrm{u}}$ & 5 & 0.699 & 0.16 & 0.3 & 5000 & 182.7 & $6 \mathrm{~N} 0.7 \mathrm{~F} 2$ & \\
\hline HD 156846 & G0V & 1.43 & 6138 & $1.9775^{\mathrm{a}}$ & HD $156846 \mathrm{~b}$ & 0.99 & -0.004 & 0.8472 & 10.45 & 359.51 & 599.0 & 10J0G8 & 4 \\
\hline HD 16760 & G5V & 0.88 & 5620 & $0.8532^{\mathrm{a}}$ & HD $16760 \mathrm{~b}$ & 1.13 & 0.053 & 0.067 & 14.3 & 465.1 & 331.1 & $14 \mathrm{~J} 0.1 \mathrm{~W} 1$ & 5 \\
\hline HD 17092 & $\mathrm{KOIII}^{\mathrm{b}}$ & 2.3 & 4650 & $10.1^{\mathrm{b}}$ & HD 17092 b & 1.29 & 0.111 & 0.166 & 4.6 & 359.9 & 880.9 & $5 \mathrm{~J} 0.1 \mathrm{G} 2$ & 6 \\
\hline HD 17156 & G0 & 1.275 & 6079 & 1.508 & HD $17156 c^{u}$ & 0.481 & -0.318 & 0.136 & 0.063 & 111.314 & 729.2 & $20 \mathrm{E}-0.3 \mathrm{G} 1$ & \\
\hline HD 181433 & K3IV & 0.78 & 4962 & $0.75521^{\mathrm{a}}$ & HD $181433 d$ & 3 & 0.477 & 0.48 & 0.54 & 2172 & 166.4 & $10 \mathrm{~N} 0.5 \mathrm{~F} 5$ & 7 \\
\hline HD 181433 & K3IV & 0.78 & 4962 & $0.75521^{\mathrm{a}}$ & HD $181433 c$ & 1.76 & 0.246 & 0.28 & 0.64 & 962 & 219.4 & $12 \mathrm{~N} 0.2 \mathrm{~F} 3$ & 7 \\
\hline HD 181433 & K3IV & 0.78 & 4962 & $0.75521^{\mathrm{a}}$ & HD $181433 b$ & 0.08 & -1.097 & 0.396 & 0.0238 & 9.3743 & 1023.6 & $8 \mathrm{E}-1.1 \mathrm{R} 4$ & 7 \\
\hline HD 181720 & G1V & 0.92 & 5781 & $1.39^{\mathrm{b}}$ & HD $181720 \mathrm{~b}$ & 1.78 & 0.250 & 0.26 & 0.37 & 956 & 345.0 & $7 \mathrm{~N} 0.3 \mathrm{~W} 3$ & 8 \\
\hline HD 190647 & G5 & 1.1 & 5628 & $1.4831^{\mathrm{a}}$ & HD 190647 b & 2.07 & 0.316 & 0.18 & 1.9 & 1038.1 & 322.4 & $2 \mathrm{~J} 0.3 \mathrm{~W} 2$ & 1 \\
\hline HD 208487 & $\mathrm{G} 2 \mathrm{~V}$ & 1.3 & 5929 & 1.15 & HD $208487 c^{u}$ & 1.8 & 0.255 & 0.19 & 0.46 & 908 & 320.7 & $9 \mathrm{~N} 0.3 \mathrm{~W} 2$ & \\
\hline HD 215497 & $\mathrm{~K} 3 \mathrm{~V}$ & 0.872 & 5113 & $0.8^{\mathrm{a}}$ & HD $215497 \mathrm{~b}$ & 0.047 & -1.328 & 0.016 & 0.02 & 3.93404 & 1430.7 & 6E-1.3R0 & 15 \\
\hline HD 215497 & K3V & 0.872 & 5113 & $0.8^{\mathrm{a}}$ & HD $215497 \mathrm{c}$ & 1.282 & 0.108 & 0.49 & 0.33 & 567.94 & 269.8 & $6 \mathrm{~N} 0.1 \mathrm{~W} 5$ & 15 \\
\hline HD 221287 & F7V & 1.25 & 6304 & $1.08237^{\mathrm{a}}$ & HD $221287 b$ & 1.25 & 0.097 & 0.08 & 3.09 & 456.1 & 397.7 & $3 \mathrm{~J} 0.1 \mathrm{~W} 1$ & 1 \\
\hline HD 2638 & G5 & 0.93 & 5192 & $0.849^{\mathrm{a}}$ & HD 2638 b & 0.044 & -1.357 & 0 & 0.48 & 3.4442 & 1546.8 & $9 \mathrm{~N}-1.4 \mathrm{R} 0$ & 10 \\
\hline HD 27894 & K2V & 0.8 & 4875 & $0.8382^{\mathrm{a}}$ & HD 27894 b & 0.122 & -0.914 & 0.049 & 0.62 & 17.991 & 866.5 & $11 \mathrm{~N}-0.9 \mathrm{G} 0$ & 10 \\
\hline HD 285968 & $\mathrm{M} 2.5 \mathrm{~V}$ & 0.49 & $3056^{\mathrm{a}}$ & 0.53 & HD $285968 c^{u}$ & 0.18 & -0.745 & 0 & 0.044 & 40 & 355.7 & $14 \mathrm{E}-0.7 \mathrm{~W} 0$ & 11 \\
\hline HD 285968 & $\mathrm{M} 2.5 \mathrm{~V}$ & 0.49 & $3056^{\mathrm{a}}$ & 0.53 & HD 285968 b & 0.066 & -1.180 & 0 & 0.0265 & 8.7836 & 587.4 & $8 \mathrm{E}-1.2 \mathrm{G} 0$ & 11 \\
\hline HD 330075 & G5 & 0.95 & 6295 & $0.7532^{\mathrm{a}}$ & HD $330075 \mathrm{~b}$ & 0.039 & -1.409 & 0 & 0.62 & 3.38773 & 1876.3 & $14 \mathrm{~N}-1.4 \mathrm{R} 0$ & 12 \\
\hline HD 38529 & G4IV & 1.48 & 5697 & 2.44 & HD $38529 d^{u}$ & 0.74 & -0.131 & 0.23 & 0.17 & 193.9 & 699.3 & $3 \mathrm{~N}-0.1 \mathrm{G} 2$ & \\
\hline HD 45364 & K0V & 0.82 & 5434 & $0.8536^{\mathrm{a}}$ & HD 45364 c & 0.8972 & -0.047 & 0.0974 & 0.6579 & 342.85 & 359.3 & 12N0W1 & 14 \\
\hline HD 45364 & K0V & 0.82 & 5434 & $0.8536^{\mathrm{a}}$ & HD $45364 \mathrm{~b}$ & 0.6813 & -0.167 & 0.1684 & 0.1872 & 226.93 & 411.8 & $3 \mathrm{~N}-0.2 \mathrm{~W} 2$ & 14 \\
\hline HD 5388 & F6V & 1.21 & $6297^{\mathrm{b}}$ & $1.91^{\mathrm{b}}$ & HD 5388 b & 1.76 & 0.246 & 0.4 & 1.96 & 777 & 440.3 & $2 \mathrm{~J} 0.2 \mathrm{~W} 4$ & 8 \\
\hline HD 63454 & $\mathrm{~K} 4 \mathrm{~V}$ & 0.8 & 4841 & $0.74053^{\mathrm{a}}$ & HD 63454 b & 0.036 & -1.444 & 0.00005 & 0.38 & 2.818049 & 1489.1 & $7 \mathrm{~N}-1.4 \mathrm{R} 0$ & 10 \\
\hline HD 65216 & G5V & 0.92 & 5666 & $0.9188^{\mathrm{a}}$ & HD 65216 b & 1.37 & 0.137 & 0.41 & 1.21 & 613.1 & 311.3 & $1 \mathrm{~J} 0.1 \mathrm{~W} 4$ & 3 \\
\hline HD 93083 & $\mathrm{~K} 3 \mathrm{~V}$ & 0.7 & 4995 & $0.85679^{\mathrm{a}}$ & HD 93083 b & 0.477 & -0.321 & 0.14 & 0.37 & 143.58 & 453.5 & $7 \mathrm{~N}-0.3 \mathrm{G} 1$ & 2 \\
\hline HIP 5158 & K5V & 0.78 & 4962 & $0.45^{\mathrm{a}}$ & HIP 5158 c & 7.7 & 0.886 & 0.14 & 15.04 & 9018 & 81.3 & 15J0.9F1 & 15 \\
\hline HIP 5158 & K5V & 0.78 & 4962 & $0.45^{\mathrm{a}}$ & HIP 5158 b & 0.89 & -0.051 & 0.54 & 1.44 & 345.63 & 235.0 & $1 \mathrm{~J}-0.1 \mathrm{~F} 5$ & 15 \\
\hline HR 8799 & A5V & 1.56 & $7430^{\mathrm{b}}$ & $1.341777^{\mathrm{a}}$ & HR 8799 d & 27 & 1.431 & 0.1 & 10 & 41054 & 112.3 & 10J1.4F1 & 9 \\
\hline HR 8799 & A5V & 1.56 & $7430^{\mathrm{b}}$ & $1.341777^{\mathrm{a}}$ & HR 8799 c & 42.9 & 1.632 & 0 & 10 & 82145 & 89.1 & $10 \mathrm{~J} 1.6 \mathrm{~F} 0$ & 9 \\
\hline HR 8799 & A5V & 1.56 & $7430^{\mathrm{b}}$ & $1.341777^{\mathrm{a}}$ & HR 8799 b & 68 & 1.833 & 0 & 7 & 164250 & 70.8 & $7 \mathrm{~J} 1.8 \mathrm{~F} 0$ & 9 \\
\hline
\end{tabular}

The data from the Extra-solar Planets Catalogue were used (Schneider et al. 2011) in this table.

$\mathrm{a}-$ the radius of the parent star was calculated with Stefan-Boltzmann's relation equation; $\mathrm{b}$ - data from reference paper; $\mathrm{u}-$ an unconfirmed extrasolar planet.

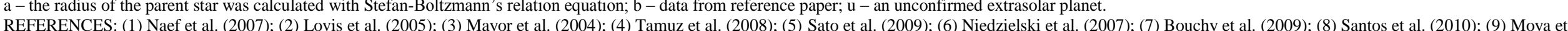

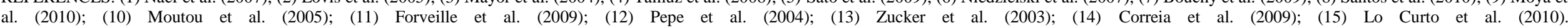


Table 4: Taxonomy identification for known EPs (except EPs which are in the table 3).

\begin{tabular}{|c|c|c|c|c|c|c|c|}
\hline Planet & Taxonomy & Planet & Taxonomy & Planet & Taxonomy & Planet & Taxonomy \\
\hline $11 \mathrm{Comb}$ & 19J0.1R2 & GJ $581 \mathrm{~b}$ & 16E-1.4G0 & "HD 109246 b & $=14 \mathrm{~N}-0.5 \mathrm{G} 1$ & "HD $160691 \mathrm{e}$ & 2J0.7F1 \\
\hline $11 \mathrm{UMi} b$ & 11J0.2R1 & GJ $581 \mathrm{e}$ & $2 \mathrm{E}-1.6 \mathrm{G} 3$ & HD $110014 b$ & 11J0.3G5 & HD 16141 b & $4 \mathrm{~N}-0.5 \mathrm{G} 4$ \\
\hline 14 And b & $5 \mathrm{~J}-0.1 \mathrm{R} 8$ & GJ $581 \mathrm{c}$ & $5 \mathrm{E}-1.1 \mathrm{G} 1$ & HD $113538 \mathrm{~b}$ & $0 \mathrm{~N}-0.1 \mathrm{~W} 6$ & HD $16175 b$ & 4J0.3W6 \\
\hline 14 Her b & 0J0.4F4 & GJ $581 \mathrm{~d}$ & $6 \mathrm{E}-0.7 \mathrm{~W} 3$ & HD $113538 \mathrm{c}$ & $1 \mathrm{~N} 0.4 \mathrm{~F} 3$ & HD $162020 \mathrm{~b}$ & 14J-1.1R3 \\
\hline 16 Cyg B b & $2 \mathrm{~J} 0.2 \mathrm{~W} 7$ & Gl 179 & $15 \mathrm{~N} 0.4 \mathrm{~F} 2$ & HD 114386 b & $1 \mathrm{~J} 0.2 \mathrm{~F} 2$ & HD $163607 \mathrm{~b}$ & $14 \mathrm{~N}-0.4 \mathrm{G} 7$ \\
\hline $18 \mathrm{Del} \mathrm{A} \mathrm{b}$ & 10J0.4G1 & G1 86 b & 4J-1G0 & HD $114729 \mathrm{~A} \mathrm{~b}$ & $16 \mathrm{~N} 0.3 \mathrm{~W} 3$ & HD $163607 \mathrm{c}$ & 2J0.4W1 \\
\hline $25 \mathrm{Sec} \mathrm{c}$ & $16 \mathrm{~N} 0.3 \mathrm{G} 3$ & Gliese $876 \mathrm{c}$ & $15 \mathrm{~N}-0.9 \mathrm{~W} 3$ & HD $114762 \mathrm{~A} \mathrm{~b}$ & $11 \mathrm{~J}-0.5 \mathrm{G} 3$ & HD $165409 \mathrm{~b}$ & $9 \mathrm{~N}-0.1 \mathrm{~W} 3$ \\
\hline $24 \mathrm{Sec} b$ & 2J0.1G1 & Gliese 876 b & 2J-0.7W0 & HD 114783 b & 1J0.1W1 & HD 164922 b & $7 \mathrm{~N} 0.3 \mathrm{~F} 1$ \\
\hline 30 Ari Bb & 10J0G3 & Gliese $876 \mathrm{~d}$ & 7E-1.7G2 & HD 11506 c & $15 \mathrm{~N}-0.2 \mathrm{G} 4$ & HD 167042 b & 2J0.1G0 \\
\hline $4 \mathrm{Uma} b$ & $7 \mathrm{~J}-0.1 \mathrm{R} 4$ & Gliese 876 e & $9 \mathrm{~N}-0.5 \mathrm{~F} 1$ & HD $11506 b$ & $3 \mathrm{~J} 0.4 \mathrm{~W} 2$ & HD $168443 \mathrm{c}$ & $17 \mathrm{~J} 0.5 \mathrm{~W} 2$ \\
\hline 42 Dra b & 3J0.1R4 & HAT-P-1 b & $10 \mathrm{~N}-1.3 \mathrm{R} 1$ & HD $116029 b$ & $2 \mathrm{~J} 0.2 \mathrm{G} 2$ & HD $168443 b$ & $8 \mathrm{~J}-0.5 \mathrm{G} 5$ \\
\hline 47 Uma c & 10N0.6F1 & HAT-P-11 b & 26E-1.3R2 & HD $117207 \mathrm{~b}$ & $2 \mathrm{~J} 0.6 \mathrm{~F} 2$ & HD 168746 b & $4 \mathrm{~N}-1.2 \mathrm{R} 1$ \\
\hline 47 Uma d & $2 \mathrm{~J} 1.1 \mathrm{~F} 2$ & HAT-P-12 b & $4 \mathrm{~N}-1.4 \mathrm{R} 0$ & HD $117618 b$ & $3 \mathrm{~N}-0.8 \mathrm{R} 4$ & HD $1690 \mathrm{~b}$ & $6 J 0.1 \mathrm{R} 6$ \\
\hline 47 Uma b & 3J0.3W0 & HAT-P-13 c & 15J0.1W7 & HD 11964 b & $12 \mathrm{~N} 0.5 \mathrm{~W} 0$ & HD $169830 \mathrm{~b}$ & $3 \mathrm{~J}-0.1 \mathrm{G} 3$ \\
\hline $51 \mathrm{Peg} \mathrm{b}$ & $9 \mathrm{~N}-1.3 \mathrm{R} 0$ & HAT-P-13 b & $16 \mathrm{~N}-1.4 \mathrm{R} 0$ & HD $11964 \mathrm{c}$ & 25E-0.6R3 & HD $169830 \mathrm{c}$ & 4J0.6W3 \\
\hline $55 \mathrm{Cnc} \mathrm{A} \mathrm{b}$ & $15 \mathrm{~N}-0.9 \mathrm{R} 0$ & HAT-P-14 b & $2 \mathrm{~J}-1.2 \mathrm{R} 1$ & HD 11977 b & 7J0.3G4 & HD $170469 \mathrm{~b}$ & $12 \mathrm{~N} 0.4 \mathrm{~W} 1$ \\
\hline $55 \mathrm{Cnc} \mathrm{Af}$ & $3 \mathrm{~N}-0.1 \mathrm{~W} 0$ & HAT-P-15 b & $2 \mathrm{~J}-1 \mathrm{R} 2$ & HD $121504 b$ & $1 \mathrm{~J}-0.5 \mathrm{G} 0$ & HD $171028 \mathrm{~b}$ & 2J0.1G6 \\
\hline $55 \mathrm{Cnc} \mathrm{A} \mathrm{c}$ & $3 \mathrm{~N}-0.6 \mathrm{G} 1$ & HAT-P-16 b & $4 \mathrm{~J}-1.4 \mathrm{R} 0$ & HD $122430 \mathrm{~b}$ & 4J0R7 & HD 17156 b & $3 \mathrm{~J}-0.8 \mathrm{R} 7$ \\
\hline $55 \mathrm{Cnc} \mathrm{Ad}$ & $4 \mathrm{~J} 0.8 \mathrm{~F} 0$ & HAT-P-17 b & $10 \mathrm{~N}-1.1 \mathrm{R} 3$ & HD $125612 \mathrm{~A} \mathrm{c}$ & $18 \mathrm{E}-1.3 \mathrm{R} 3$ & HD $173416 b$ & 3J0.1R2 \\
\hline $55 \mathrm{Cnc} \mathrm{A} \mathrm{e}$ & $9 \mathrm{E}-1.8 \mathrm{R} 1$ & HAT-P-17 c & $1 \mathrm{~J} 0.4 \mathrm{~F} 1$ & HD $125612 \mathrm{~A} \mathrm{~b}$ & $3 \mathrm{~J} 0.1 \mathrm{~W} 5$ & HD $175541 \mathrm{~b}$ & 11N0G3 \\
\hline 6 Lyn b & 2J0.3G1 & HAT-P-18 b & $4 \mathrm{~N}-1.3 \mathrm{R} 1$ & HD $125612 \mathrm{~A} \mathrm{~d}$ & $7 \mathrm{~J} 0.6 \mathrm{~F} 3$ & HD $177830 \mathrm{~b}$ & 1J0.1G0 \\
\hline 61 Vir c & $18 \mathrm{E}-0.7 \mathrm{G} 1$ & HAT-P-19 b & $5 \mathrm{~N}-1.3 \mathrm{R} 1$ & HD $12661 \mathrm{~b}$ & $2 \mathrm{~J}-0.1 \mathrm{~W} 4$ & HD $177830 \mathrm{c}$ & $3 \mathrm{~N}-0.3 \mathrm{G} 3$ \\
\hline 61 Vir d & 23E-0.3G4 & HAT-P-2 b & $9 \mathrm{~J}-1.2 \mathrm{R} 5$ & HD $12661 \mathrm{c}$ & 2J0.4W0 & HD $178911 \mathrm{~B} \mathrm{~b}$ & $6 \mathrm{~J}-0.5 \mathrm{G} 1$ \\
\hline 61 Vir b & $5 \mathrm{E}-1.3 \mathrm{R} 1$ & HAT-P-20 b & $7 \mathrm{~J}-1.4 \mathrm{R} 0$ & HD $126614 b$ & 7N0.4W4 & HD $179079 \mathrm{~b}$ & $25 \mathrm{E}-1 \mathrm{R} 1$ \\
\hline 70 Vir b & $7 \mathrm{~J}-0.3 \mathrm{G} 4$ & HAT-P-21 b & $4 \mathrm{~J}-1.3 \mathrm{R} 2$ & HD $128311 b$ & 2J0W3 & HD 179949 b & $18 \mathrm{~N}-1.3 \mathrm{R} 0$ \\
\hline alf Ari b & 2J0.1R3 & HAT-P-22 b & $2 \mathrm{~J}-1.4 \mathrm{R} 0$ & HD $128311 \mathrm{c}$ & $3 \mathrm{~J} 0.2 \mathrm{~F} 2$ & HD 180314 b & 22J0.1G3 \\
\hline $\mathrm{BD}+48738 \mathrm{~b}$ & 17 N0G2 & HAT-P-23 b & 2J-1.6R1 & HD 130322 b & $1 \mathrm{~J}-1.1 \mathrm{R} 0$ & HD 180902 b & 2J0.1G1 \\
\hline $\mathrm{BD}+48738 \mathrm{~b}$ & 17 NOG2 & HAT-P-24 b & $13 \mathrm{~N}-1.3 \mathrm{R} 1$ & HD 131496 b & $2 \mathrm{~J} 0.3 \mathrm{G} 2$ & HD $181342 b$ & $3 \mathrm{~J} 0.3 \mathrm{G} 2$ \\
\hline $\mathrm{BD}+201790 \mathrm{~b}$ & $7 \mathrm{~J}-1.2 \mathrm{G} 1$ & HAT-P-25 b & $11 \mathrm{~N}-1.3 \mathrm{R} 0$ & HD $131664 b$ & $18 \mathrm{~J} 0.5 \mathrm{~F} 6$ & HD $183263 \mathrm{~b}$ & $4 \mathrm{~J} 0.2 \mathrm{~W} 4$ \\
\hline BD-10 3166 b & $9 \mathrm{~N}-1.3 \mathrm{R} 1$ & HAT-P-26 b & 19E-1.3R1 & HD $134987 \mathrm{c}$ & $15 \mathrm{~N} 0.8 \mathrm{~F} 1$ & HD $183263 \mathrm{c}$ & 4J0.6F3 \\
\hline BD-17 $63 \mathrm{~b}$ & $5 \mathrm{~J} 0.1 \mathrm{~F} 5$ & HAT-P-27 b & $12 \mathrm{~N}-1.4 \mathrm{R} 1$ & HD $134987 \mathrm{~b}$ & $2 \mathrm{~J}-0.1 \mathrm{G} 2$ & HD $185269 \mathrm{~b}$ & $17 \mathrm{~N}-1.1 \mathrm{R} 3$ \\
\hline CoRoT-1 b & $1 \mathrm{~J}-1.6 \mathrm{R} 0$ & HAT-P-28 b & $12 \mathrm{~N}-1.4 \mathrm{R} 1$ & HD $136418 b$ & 2J0.1G3 & HD $187123 b$ & $10 \mathrm{~N}-1.4 \mathrm{R} 0$ \\
\hline CoRoT-10 b & 3J-1G5 & HAT-P-29 b & $14 \mathrm{~N}-1.2 \mathrm{R} 1$ & HD $137388 \mathrm{~b}$ & $4 \mathrm{~N}-0.1 \mathrm{~W} 4$ & HD $187123 \mathrm{c}$ & $2 \mathrm{~J} 0.7 \mathrm{~F} 3$ \\
\hline CoRoT-11 b & $2 \mathrm{~J}-1.4 \mathrm{R} 0$ & HAT-P-3 b & $11 \mathrm{~N}-1.4 \mathrm{R} 0$ & HD $13931 b$ & $2 \mathrm{~J} 0.7 \mathrm{~F} 0$ & HD 18742 b & $3 \mathrm{~J} 0.3 \mathrm{G} 2$ \\
\hline CoRoT-12 b & $1 \mathrm{~J}-1.4 \mathrm{R} 1$ & HAT-P-30 b & $14 \mathrm{~N}-1.4 \mathrm{R} 0$ & HD $139357 \mathrm{~b}$ & 10J0.4G1 & HD 188015 b & 1J0.1W2 \\
\hline CoRoT-13 b & $1 \mathrm{~J}-1.3 \mathrm{R} 0$ & HAT-P-31 b & $2 \mathrm{~J}-1.3 \mathrm{R} 2$ & HD $141937 \mathrm{~b}$ & $10 \mathrm{~J} 0.2 \mathrm{~W} 4$ & HD $189733 b$ & $1 \mathrm{~J}-1.5 \mathrm{R} 0$ \\
\hline CoRoT-14 b & $8 \mathrm{~J}-1.6 \mathrm{R} 0$ & HAT-P-32 b & $17 \mathrm{~N}-1.5 \mathrm{R} 2$ & HD $142 \mathrm{~A} \mathrm{~b}$ & 1J0W4 & HD 190228 b & $5 \mathrm{~J} 0.4 \mathrm{~W} 4$ \\
\hline CoRoT-16 b & $10 \mathrm{~N}-1.2 \mathrm{R} 3$ & HAT-P-33 b & $14 \mathrm{~N}-1.3 \mathrm{R} 1$ & HD $142022 \mathrm{~A} \mathrm{~b}$ & $5 \mathrm{~J} 0.5 \mathrm{~F} 5$ & HD $190360 \mathrm{c}$ & $18 \mathrm{E}-0.9 \mathrm{R} 0$ \\
\hline CoRoT-17 b & $2 \mathrm{~J}-1.3 \mathrm{R} 0$ & HAT-P-4 b & $13 \mathrm{~N}-1.4 \mathrm{R} 0$ & HD 142245 b & 2J0.4G3 & HD $190360 \mathrm{~b}$ & 2J0.6F4 \\
\hline CoRoT-18 b & $3 \mathrm{~J}-1.5 \mathrm{R} 1$ & HAT-P-5 b & $1 \mathrm{~J}-1.4 \mathrm{R} 0$ & HD 142415 b & 2J0W5 & HD 190984 b & 3J0.7F6 \\
\hline CoRoT-19 b & $1 \mathrm{~J}-1.3 \mathrm{R} 0$ & HAT-P-6 b & $1 \mathrm{~J}-1.3 \mathrm{R} 0$ & HD 145377 b & $6 \mathrm{~J}-0.3 \mathrm{G} 3$ & HD $192263 b$ & $13 \mathrm{~N}-0.8 \mathrm{G} 0$ \\
\hline CoRoT-2 b & $3 \mathrm{~J}-1.6 \mathrm{R} 0$ & HAT-P-7 b & $2 \mathrm{~J}-1.4 \mathrm{R} 0$ & HD $145457 \mathrm{~b}$ & $3 \mathrm{~J}-0.1 \mathrm{R} 1$ & HD $192310 \mathrm{~b}$ & 17E-0.5G1 \\
\hline CoRoT-20 b & 4J-1R6 & HAT-P-8 b & $1 \mathrm{~J}-1.3 \mathrm{R} 0$ & HD $1461 \mathrm{c}$ & $6 \mathrm{E}-1 \mathrm{R} 0$ & HD $192310 \mathrm{c}$ & $24 \mathrm{E} 0.1 \mathrm{~W} 3$ \\
\hline CoRoT-21 b & $3 \mathrm{~J}-1.4 \mathrm{R} 0$ & HAT-P-9 b & $12 \mathrm{~N}-1.3 \mathrm{R} 0$ & HD 1461 b & $8 \mathrm{E}-1.2 \mathrm{R} 1$ & HD $192699 \mathrm{~b}$ & 3J0.1G1 \\
\hline CoRoT-23 b & $3 \mathrm{~J}-1.3 \mathrm{R} 2$ & HD $102117 b$ & $3 \mathrm{~N}-0.8 \mathrm{R} 1$ & HD $147513 b$ & $1 \mathrm{~J} 0.1 \mathrm{~W} 3$ & HD $195019 b$ & $4 \mathrm{~J}-0.9 \mathrm{R} 0$ \\
\hline CoRoT-3 b & $22 \mathrm{~J}-1.2 \mathrm{R} 0$ & HD $102195 b$ & $8 \mathrm{~N}-1.3 \mathrm{R} 0$ & HD $148156 b$ & $16 \mathrm{~N} 0.4 \mathrm{~W} 5$ & HD $196050 \mathrm{~b}$ & $3 \mathrm{~J} 0.4 \mathrm{~W} 2$ \\
\hline CoRoT-4 b & $13 N-1 R 0$ & HD $102272 \mathrm{c}$ & $3 \mathrm{~J} 0.2 \mathrm{G} 7$ & HD $148427 \mathrm{~b}$ & 18 NOG2 & HD $196885 \mathrm{~A} \mathrm{~b}$ & 3J0.4W5 \\
\hline CoRoT-5 b & $9 \mathrm{~N}-1.3 \mathrm{R} 1$ & HD $102272 b$ & $6 \mathrm{~J}-0.2 \mathrm{R} 1$ & HD $149026 b$ & $7 \mathrm{~N}-1.4 \mathrm{R} 0$ & HD 19994 b & $2 \mathrm{~J} 0.2 \mathrm{G} 3$ \\
\hline CoRoT-6 b & 3J-1.1R1 & HD $102329 b$ & $6 \mathrm{~J} 0.3 \mathrm{G} 2$ & HD 1502 b & 3J0.1G1 & HD $200964 \mathrm{c}$ & $1 \mathrm{~J} 0.3 \mathrm{G} 2$ \\
\hline CoRoT-7 b & $5 \mathrm{E}-1.8 \mathrm{R} 0$ & HD 102956 b & $1 \mathrm{~J}-1.1 \mathrm{R} 0$ & HD $152581 \mathrm{~b}$ & $2 \mathrm{~J} 0.2 \mathrm{G} 2$ & HD 200964 b & 2J0.2G0 \\
\hline CoRoT-7 c & $8 \mathrm{E}-1.3 \mathrm{R} 0$ & HD $104985 b$ & $6 \mathrm{~J}-0.1 \mathrm{R} 0$ & HD $153950 \mathrm{~b}$ & $3 \mathrm{~J} 0.1 \mathrm{~W} 3$ & HD $202206 b$ & $17 \mathrm{~J}-0.1 \mathrm{~W} 4$ \\
\hline CoRoT-8b & $4 \mathrm{~N}-1.2 \mathrm{R} 0$ & HD $106252 b$ & $8 \mathrm{~J} 0.4 \mathrm{~F} 5$ & HD 154672 b & $5 \mathrm{~J}-0.2 \mathrm{G} 6$ & HD $202206 \mathrm{c}$ & 2J0.4F3 \\
\hline CoRoT-9 b & $16 \mathrm{~N}-0.4 \mathrm{G} 1$ & HD $106270 \mathrm{~b}$ & $11 \mathrm{~J} 0.6 \mathrm{~W} 4$ & HD 154857 b & 2J0.1G5 & HD 20367 b & $1 \mathrm{~J} 0.1 \mathrm{~W} 2$ \\
\hline eps Eridani A b & $2 \mathrm{~J} 0.5 \mathrm{~F} 7$ & HD 10647 b & 17N0.3W1 & HD $156411 b$ & $14 \mathrm{~N} 0.3 \mathrm{~W} 2$ & HD 2039 b & $5 \mathrm{~J} 0.3 \mathrm{~W} 7$ \\
\hline Fomalhaut b & $3 \mathrm{~J} 2.1 \mathrm{~F} 1$ & HD 10697 b & $6 \mathrm{~J} 0.3 \mathrm{~W} 1$ & HD $156668 \mathrm{~b}$ & $4 \mathrm{E}-1.3 \mathrm{R} 0$ & HD $204941 \mathrm{~b}$ & $5 \mathrm{~N} 0.4 \mathrm{~F} 4$ \\
\hline gam 1 Leo A b & 9J0.1R1 & HD $108147 b$ & $5 N-1 R 5$ & HD 158038 b & 2J0.2G3 & HD $205739 \mathrm{~b}$ & 1J0G3 \\
\hline gam Ceph A b & 2J0.3G0 & HD $108863 b$ & 3J0.1G1 & HD $160691 \mathrm{~d}$ & 10N0W1 & HD $206610 b$ & $2 \mathrm{~J} 0.2 \mathrm{G} 2$ \\
\hline GJ 1214 b & $6 \mathrm{E}-1.9 \mathrm{G} 3$ & HD $108874 \mathrm{c}$ & $1 \mathrm{~J} 0.4 \mathrm{~F} 3$ & HD $160691 \mathrm{c}$ & 11E-1R2 & HD $208487 \mathrm{~b}$ & $8 \mathrm{~N}-0.3 \mathrm{G} 2$ \\
\hline GJ 436 b & $23 \mathrm{E}-1.5 \mathrm{R} 2$ & HD 108874 b & 1J0W1 & HD $160691 \mathrm{~b}$ & $2 \mathrm{~J} 0.2 \mathrm{~W} 1$ & HD $20868 \mathrm{~b}$ & 2J0W8 \\
\hline
\end{tabular}


Table 4: continued.

\begin{tabular}{|c|c|c|c|c|c|c|c|}
\hline Planet & Taxonomy & Planet & Taxonomy & Planet & Taxonomy & Planet & Taxonomy \\
\hline HD 209458 b & $13 \mathrm{~N}-1.3 \mathrm{R} 0$ & HD 47536 b & $\begin{array}{l}5 \mathrm{~J} 0.2 \mathrm{R} 2 \\
\end{array}$ & $\begin{array}{ll}\text { HD 98219 b } \\
\end{array}$ & $2 \mathrm{~J} 0.1 \mathrm{G} 2$ & $\begin{array}{l}\text { Saturn } \\
\end{array}$ & $\overline{~ 6 N 1 F 1 g}$ \\
\hline HD $210277 b$ & 1J0W5 & HD 49674 b & $2 \mathrm{~N}-1.2 \mathrm{R} 2$ & HD 99492 b & $2 \mathrm{~N}-0.9 \mathrm{G} 3$ & tau Boo b & $4 \mathrm{~J}-1.3 \mathrm{R} 0$ \\
\hline HD 210702 b & $2 \mathrm{~J} 0.1 \mathrm{G} 2$ & HD 50499 b & $2 \mathrm{~J} 0.6 \mathrm{~F} 2$ & HD $99492 \mathrm{c}$ & 7N0.7F1 & TrES-2 b & $1 \mathrm{~J}-1.4 \mathrm{R} 0$ \\
\hline HD $212771 \mathrm{~b}$ & $2 \mathrm{~J} 0.1 \mathrm{G} 1$ & HD $50554 \mathrm{~b}$ & $5 \mathrm{~J} 0.4 \mathrm{~W} 5$ & HD $99706 \mathrm{~b}$ & 1J0.3G4 & TrES-3 b & $2 \mathrm{~J}-1.6 \mathrm{R} 0$ \\
\hline HD $213240 \mathrm{~b}$ & 5J0.3W5 & HD $52265 \mathrm{~b}$ & $1 \mathrm{~J}-0.3 \mathrm{G} 4$ & HIP 13044 b & $1 \mathrm{~J}-0.9 \mathrm{R} 3$ & TrES-4 b & $17 \mathrm{~N}-1.3 \mathrm{R} 0$ \\
\hline HD $216435 b$ & $1 \mathrm{~J} 0.4 \mathrm{~W} 1$ & HD 5319 b & $2 \mathrm{~J} 0.2 \mathrm{G} 1$ & HIP $14810 \mathrm{~d}$ & $11 \mathrm{~N} 0.3 \mathrm{~W} 2$ & ups And d & $10 \mathrm{~J} 0.4 \mathrm{~W} 3$ \\
\hline HD $216437 b$ & $2 \mathrm{~J} 0.4 \mathrm{~W} 3$ & HD $5891 \mathrm{~b}$ & $8 \mathrm{~J}-0.1 \mathrm{R} 1$ & HIP $14810 \mathrm{c}$ & $1 \mathrm{~J}-0.3 \mathrm{G} 2$ & ups And b & $13 \mathrm{~N}-1.2 \mathrm{R} 0$ \\
\hline HD $216770 \mathrm{~b}$ & $12 \mathrm{~N}-0.3 \mathrm{G} 4$ & HD $62509 \mathrm{~b}$ & $3 \mathrm{~J} 0.2 \mathrm{G} 0$ & HIP $14810 b$ & $4 \mathrm{~J}-1.2 \mathrm{R} 1$ & ups And c & $15 \mathrm{~J}-0.1 \mathrm{G} 2$ \\
\hline HD $217107 b$ & 1J-1.1R1 & HD 6434 b & $7 \mathrm{~N}-0.9 \mathrm{G} 2$ & HIP $57050 \mathrm{~b}$ & $0 \mathrm{~N}-0.8 \mathrm{~W} 3$ & ups And e & 1J0.7F0 \\
\hline HD $217107 c$ & 2J0.7F5 & HD 6718 b & 2J0.6F1 & HIP $57274 d$ & 10N0W3 & V391 Peg b & 3J0.2G0 \\
\hline HD 217786 b & $13 \mathrm{~J} 0.4 \mathrm{~W} 4$ & HD 68988 b & $2 \mathrm{~J}-1.1 \mathrm{R} 1$ & HIP 57274 b & $11 \mathrm{E}-1.2 \mathrm{G} 2$ & WASP-1 b & $16 \mathrm{~N}-1.4 \mathrm{R} 0$ \\
\hline HD 218566 b & $4 \mathrm{~N}-0.2 \mathrm{~W} 3$ & HD $69830 \mathrm{~b}$ & 10E-1.1R1 & HIP $57274 \mathrm{c}$ & $8 \mathrm{~N}-0.7 \mathrm{G} 1$ & WASP-10 b & $3 \mathrm{~J}-1.4 \mathrm{R} 1$ \\
\hline HD 219828 b & 21E-1.3R 0 & HD $69830 \mathrm{c}$ & $12 \mathrm{E}-0.7 \mathrm{G} 1$ & HIP $75458 \mathrm{~b}$ & 9J0.1G7 & WASP-11 b & $9 \mathrm{~N}-1.4 \mathrm{R} 0$ \\
\hline HD $222582 \mathrm{~b}$ & 8J0.1W7 & HD $69830 \mathrm{~d}$ & $18 \mathrm{E}-0.2 \mathrm{~W} 1$ & HR 810 b & $2 \mathrm{~J} 0 \mathrm{G} 2$ & WASP-12 b & 1J-1.6R0 \\
\hline HD $224693 b$ & $13 \mathrm{~N}-0.6 \mathrm{R} 1$ & HD $70642 \mathrm{~b}$ & $2 \mathrm{~J} 0.5 \mathrm{~F} 1$ & kappa CrB b & $2 \mathrm{~J} 0.4 \mathrm{~W} 2$ & WASP-14 b & $8 \mathrm{~J}-1.4 \mathrm{R} 1$ \\
\hline HD 23079 b & $3 \mathrm{~J} 0.2 \mathrm{~W} 0$ & HD 7199 b & $5 \mathrm{~N} 0.1 \mathrm{~W} 2$ & Kepler-10 b & $0 \mathrm{E}-1.8 \mathrm{R} 0$ & WASP-15 b & $10 \mathrm{~N}-0.3 \mathrm{G} 0$ \\
\hline HD $231701 b$ & $1 \mathrm{~J}-0.3 \mathrm{G} 1$ & HD $72659 \mathrm{~b}$ & $3 \mathrm{~J} 0.7 \mathrm{~F} 2$ & Kepler-10 c & $0 \mathrm{~N}-0.6 \mathrm{G} 0$ & WASP-16 b & $16 \mathrm{~N}-1.4 \mathrm{R} 0$ \\
\hline HD 23596 b & $8 \mathrm{~J} 0.5 \mathrm{~W} 3$ & HD $73256 b$ & $2 \mathrm{~J}-1.4 \mathrm{R} 0$ & Kepler-11 c & 14E-1R0 & WASP-17 b & $9 \mathrm{~N}-1.3 \mathrm{R} 0$ \\
\hline HD $240237 b$ & 5J0.3R4 & HD $73267 b$ & $3 \mathrm{~J} 0.3 \mathrm{~F} 3$ & Kepler-11 g & $18 \mathrm{~N}-0.3 \mathrm{G} 0$ & WASP- $18 \mathrm{~b}$ & 10J-1.7R0 \\
\hline HD 25171 b & $1 \mathrm{~N} 0.5 \mathrm{~W} 1$ & HD $73526 \mathrm{~b}$ & $3 \mathrm{~J}-0.2 \mathrm{G} 2$ & Kepler-11 b & 4E-1R0 & WASP-19 b & $1 \mathrm{~J}-1.8 \mathrm{R} 0$ \\
\hline HD 27442 b & 1J0.1G1 & HD $73526 c$ & 3J0G1 & Kepler- $11 \mathrm{f}$ & $4 \mathrm{M}-0.6 \mathrm{G} 0$ & WASP-2 b & $16 \mathrm{~N}-1.5 \mathrm{R} 0$ \\
\hline HD $28185 b$ & 6J0W1 & HD $73534 b$ & $1 \mathrm{~J} 0.5 \mathrm{~W} 0$ & Kepler-11 d & $6 \mathrm{E}-0.8 \mathrm{R} 0$ & WASP- $21 \mathrm{~b}$ & $6 \mathrm{~N}-1.3 \mathrm{R} 0$ \\
\hline HD $28254 \mathrm{~b}$ & $1 \mathrm{~J} 0.3 \mathrm{~W} 8$ & HD 74156 b & $2 \mathrm{~J}-0.5 \mathrm{G} 6$ & Kepler-11 e & $8 \mathrm{E}-0.7 \mathrm{G} 0$ & WASP- $22 \mathrm{~b}$ & $1 \mathrm{~N}-1.3 \mathrm{R} 0$ \\
\hline HD $28678 b$ & $2 \mathrm{~J} 0.1 \mathrm{G} 2$ & HD $74156 \mathrm{~d}$ & 7N0G3 & Kepler-12 b & $8 \mathrm{~N}-1.3 \mathrm{R} 0$ & WASP- $23 \mathrm{~b}$ & $16 \mathrm{~N}-1.4 \mathrm{R} 1$ \\
\hline HD $290327 b$ & $3 \mathrm{~J} 0.5 \mathrm{~F} 1$ & HD $74156 c$ & $8 \mathrm{~J} 0.5 \mathrm{~W} 4$ & Kepler-16(AB) b & $6 \mathrm{~N}-0.2 \mathrm{~W} 0$ & WASP-24 b & 1J-1.4R0 \\
\hline HD30177 b & $8 \mathrm{~J} 0.4 \mathrm{~F} 2$ & HD 7449 b & $1 \mathrm{~J} 0.4 \mathrm{~W} 8$ & Kepler-17 b & $2 \mathrm{~J}-1.6 \mathrm{R} 0$ & WASP- $25 \mathrm{~b}$ & $1 \mathrm{~N}-1.3 \mathrm{R} 0$ \\
\hline HD 30562 b & 1J0.4W8 & HD $7449 \mathrm{c}$ & 2J0.7F5 & Kepler-4 b & 24E-1.3R 0 & WASP-26 b & 1J-1.4R0 \\
\hline HD 30856 b & $2 \mathrm{~J} 0.3 \mathrm{G} 2$ & HD $75289 b$ & $8 \mathrm{~N}-1.3 \mathrm{R} 0$ & Kepler-5 b & $2 \mathrm{~J}-1.3 \mathrm{R} 0$ & WASP- $28 \mathrm{~b}$ & $1 \mathrm{~N}-1.3 \mathrm{R} 0$ \\
\hline HD $31253 b$ & $1 \mathrm{~N} 0.1 \mathrm{G} 3$ & HD $75898 \mathrm{~b}$ & $3 \mathrm{~J} 0.1 \mathrm{G} 1$ & Kepler-6 b & $12 \mathrm{~N}-1.3 \mathrm{R} 0$ & WASP-29 b & $5 \mathrm{~N}-1.3 \mathrm{R} 0$ \\
\hline HD $32518 b$ & $3 \mathrm{~J}-0.2 \mathrm{R} 0$ & HD $76700 \mathrm{~b}$ & $4 \mathrm{~N}-1.3 \mathrm{R} 0$ & Kepler-7 b & $8 \mathrm{~N}-1.2 \mathrm{R} 1$ & WASP-3 b & $2 \mathrm{~J}-1.5 \mathrm{R} 0$ \\
\hline HD $33142 b$ & 1J0G2 & HD 7924 b & $9 \mathrm{E}-1.2 \mathrm{R} 2$ & Kepler-8 b & $11 \mathrm{~N}-1.3 \mathrm{R} 0$ & WASP-31 b & $0 \mathrm{~N}-1.3 \mathrm{R} 0$ \\
\hline HD $33283 b$ & $6 \mathrm{~N}-0.8 \mathrm{R} 5$ & HD $80606 \mathrm{~b}$ & $4 \mathrm{~J}-0.3 \mathrm{G} 9$ & KOI-196 b & $9 \mathrm{~N}-1.5 \mathrm{R} 0$ & WASP-32 b & $4 \mathrm{~J}-1.4 \mathrm{R} 0$ \\
\hline HD 33564 b & 9J0W3 & HD $81040 \mathrm{~b}$ & 7J0.3F5 & KOI- $423 \mathrm{~b}$ & $18 \mathrm{~J}-0.8 \mathrm{R} 1$ & WASP-33b & $5 \mathrm{~J}-1.6 \mathrm{R} 0$ \\
\hline HD $34445 b$ & $15 \mathrm{~N} 0.3 \mathrm{~W} 3$ & HD $81688 b$ & $3 \mathrm{~J}-0.1 \mathrm{R} 0$ & KOI- $428 \mathrm{~b}$ & $2 \mathrm{~J}-1.1 \mathrm{R} 0$ & WASP-34 b & $11 \mathrm{~N}-1.3 \mathrm{R} 0$ \\
\hline HD 3651 b & $4 \mathrm{~N}-0.5 \mathrm{G} 6$ & HD $82886 b$ & $1 \mathrm{~J} 0.2 \mathrm{G} 3$ & ksi Aql b & $3 \mathrm{~J}-0.2 \mathrm{R} 0$ & WASP-36 b & 2J-1.6R0 \\
\hline HD $37124 \mathrm{c}$ & $12 \mathrm{~N} 0.2 \mathrm{~W} 1$ & HD $82943 \mathrm{c}$ & $2 \mathrm{~J}-0.1 \mathrm{G} 4$ & Lupus-TR-3 b & $15 \mathrm{~N}-1.3 \mathrm{R} 0$ & WASP-37 b & $2 \mathrm{~J}-1.4 \mathrm{R} 0$ \\
\hline HD 37124 b & $13 \mathrm{~N}-0.3 \mathrm{G} 0$ & HD $82943 \mathrm{~b}$ & $2 \mathrm{~J} 0.1 \mathrm{~W} 2$ & OGLE-TR-10 b & $13 \mathrm{~N}-1.4 \mathrm{R} 0$ & WASP-39 & $5 \mathrm{~N}-1.3 \mathrm{R} 0$ \\
\hline HD $37124 d$ & 13N0.4F2 & HD $83443 b$ & $8 \mathrm{~N}-1.4 \mathrm{R} 0$ & OGLE-TR-111 b & $10 \mathrm{~N}-1.3 \mathrm{R} 0$ & WASP-4 b & 1J-1.6R0 \\
\hline HD $38529 b$ & $14 \mathrm{~N}-0.9 \mathrm{R} 2$ & HD 8535 b & $13 \mathrm{~N} 0.4 \mathrm{~W} 2$ & OGLE-TR-113 b & 1J-1.6R0 & WASP-41 b & $17 \mathrm{~N}-1.4 \mathrm{R} 0$ \\
\hline HD $38529 c$ & 18J0.6W4 & HD 8574 b & $2 \mathrm{~J}-0.1 \mathrm{G} 3$ & OGLE-TR-132 b & $1 \mathrm{~J}-1.5 \mathrm{R} 0$ & WASP-43 b & $2 \mathrm{~J}-1.8 \mathrm{R} 0$ \\
\hline HD $38801 \mathrm{~b}$ & $11 \mathrm{~J} 0.2 \mathrm{~W} 0$ & HD 86081b & $2 \mathrm{~J}-1.4 \mathrm{R} 0$ & OGLE-TR-182 b & $1 \mathrm{~J}-1.3 \mathrm{R} 0$ & WASP-44 b & $1 \mathrm{~J}-1.5 \mathrm{R} 0$ \\
\hline HD 39091 b & $10 \mathrm{~J} 0.5 \mathrm{~W} 6$ & HD $86264 b$ & 7J0.5W7 & OGLE-TR-211 b & $14 \mathrm{~N}-1.3 \mathrm{R} 0$ & WASP-45 b & $1 \mathrm{~J}-1.4 \mathrm{R} 0$ \\
\hline HD 40979 b & $3 \mathrm{~J}-0.1 \mathrm{G} 3$ & HD $8673 b$ & $14 \mathrm{~J} 0.5 \mathrm{~W} 7$ & PRS $1257+12 b$ & 0M-0.7P0 & WASP-46 b & $2 \mathrm{~J}-1.6 \mathrm{R} 0$ \\
\hline $\mathrm{HD} 41004 \mathrm{~A} \mathrm{~b}$ & $3 \mathrm{~J} 0.2 \mathrm{~W} 4$ & HD $87883 b$ & 12J0.6F5 & PRS $1257+12 \mathrm{~d}$ & $4 \mathrm{E}-0.3 \mathrm{P} 0$ & WASP-48 b & $18 \mathrm{~N}-1.5 \mathrm{R} 0$ \\
\hline HD 4113 b & 2J0.1W9 & HD $88133 b$ & $4 \mathrm{~N}-1.3 \mathrm{R} 1$ & PRS $1257+12 \mathrm{c}$ & $4 \mathrm{E}-0.4 \mathrm{P} 0$ & WASP-5 b & $2 \mathrm{~J}-1.6 \mathrm{R} 0$ \\
\hline HD $4203 \mathrm{~b}$ & $2 \mathrm{~J} 0.1 \mathrm{~W} 5$ & HD $89307 b$ & $2 \mathrm{~J} 0.5 \mathrm{~F} 2$ & PSR $1719-14 b$ & $1 \mathrm{~J}-3.4 \mathrm{P} 1$ & WASP-50 b & $1 \mathrm{~J}-1.5 \mathrm{R} 0$ \\
\hline HD $4208 \mathrm{~b}$ & $15 \mathrm{~N} 0.2 \mathrm{~W} 0$ & HD 89744 b & $7 \mathrm{~J}-0.1 \mathrm{G} 7$ & Qatar-1 b & $1 \mathrm{~J}-1.6 \mathrm{R} 0$ & WASP-51 b & $14 \mathrm{~N}-1.4 \mathrm{R} 0$ \\
\hline HD $4308 \mathrm{~b}$ & 13E-0.9R3 & HD 92788 b & 4J0W3 & rho $\mathrm{CrB} b$ & $1 \mathrm{~J}-0.7 \mathrm{G} 0$ & WASP-6 b & $9 \mathrm{~N}-1.4 \mathrm{R} 1$ \\
\hline HD 4313 b & $2 \mathrm{~J} 0.1 \mathrm{G} 0$ & HD 9446 b & $13 \mathrm{~N}-0.7 \mathrm{G} 2$ & Venus & $15 \mathrm{M}-0.1 \mathrm{G} 0 \mathrm{t}$ & WASP-7 b & $18 \mathrm{~N}-1.2 \mathrm{R} 0$ \\
\hline HD $43197 \mathrm{~b}$ & 11N0W8 & HD 9446 c & $2 \mathrm{~J}-0.2 \mathrm{G} 1$ & Uranus & $15 \mathrm{E} 1.3 \mathrm{~F} 0 \mathrm{i}$ & WASP-8 b & 2J-1.1R3 \\
\hline HD $44219 b$ & 11N0.1W6 & HD $95089 b$ & $1 \mathrm{~J} 0.2 \mathrm{G} 2$ & Earth & 1E0W0t & XO-2 b & $11 \mathrm{~N}-1.4 \mathrm{R} 0$ \\
\hline HD $45350 \mathrm{~b}$ & $2 \mathrm{~J} 0.3 \mathrm{~W} 8$ & HD $96063 \mathrm{~b}$ & 17 N0G3 & Jupiter & 1J0.7F0g & $\mathrm{XO}-3 \mathrm{~b}$ & $12 \mathrm{~J}-1.3 \mathrm{R} 3$ \\
\hline HD $46375 b$ & $5 \mathrm{~N}-1.4 \mathrm{R} 0$ & HD $96127 \mathrm{~b}$ & 4J0.1R3 & Mercury & $1 \mathrm{M}-0.4 \mathrm{G} 2 \mathrm{t}$ & XO-4 b & $2 \mathrm{~J}-1.3 \mathrm{R} 0$ \\
\hline HD $47186 \mathrm{~b}$ & $23 \mathrm{E}-1.3 \mathrm{R} 0$ & HD $96167 b$ & $13 \mathrm{~N} 0.1 \mathrm{G} 7$ & Neptune & 1N1.5F0i & $\mathrm{XO}-5 \mathrm{~b}$ & $1 \mathrm{~J}-1.3 \mathrm{R} 0$ \\
\hline HD $47186 \mathrm{c}$ & 7N0.4W2 & HD 97658 b & $6 \mathrm{E}-1.1 \mathrm{R} 1$ & Mars & $2 \mathrm{M} 0.2 \mathrm{~W} 1 \mathrm{t}$ & & \\
\hline
\end{tabular}

The data from the Extra-solar Planets Catalogue were used (Schneider et al. 2011) in this table. 